Article

\title{
Determining the Social, Economic, Political and Technical Factors Significant to the Success of Dynamic Wireless Charging Systems through a Process of Stakeholder Engagement
}

\author{
Shamala Gadgil ${ }^{1,2, *(\mathbb{D})}$, Karthikeyan Ekambaram ${ }^{1}\left(\mathbb{D}\right.$, Huw Davies ${ }^{1}\left(\mathbb{D}\right.$, Andrew Jones ${ }^{3}$ (D) and Stewart Birrell ${ }^{1}$ (D) \\ 1 Research Institute for Clean Growth and Future Mobility, Coventry University, Coventry CV1 5FB, UK; \\ sendtokarthick@gmail.com (K.E.); ac2616@coventry.ac.uk (H.D.); ad2998@coventry.ac.uk (S.B.) \\ 2 Transport and Innovation Department, Coventry City Council, Coventry CV1 2GN, UK \\ 3 Research Institute for Responsible Business, Economies \& Society, Coventry University, \\ Coventry CV1 5FB, UK; ac0766@coventry.ac.uk \\ * Correspondence: evanss42@uni.coventry.ac.uk
}

check for

updates

Citation: Gadgil, S.; Ekambaram, K.; Davies, H.; Jones, A.; Birrell, S. Determining the Social, Economic, Political and Technical Factors Significant to the Success of Dynamic Wireless Charging Systems through a Process of Stakeholder Engagement. Energies 2022, 15, 930. https:// doi.org/10.3390/en15030930

Academic Editor: Adel El-Shahat

Received: 7 December 2021

Accepted: 25 January 2022

Published: 27 January 2022

Publisher's Note: MDPI stays neutral with regard to jurisdictional claims in published maps and institutional affiliations.

Copyright: (C) 2022 by the authors. Licensee MDPI, Basel, Switzerland. This article is an open access article distributed under the terms and conditions of the Creative Commons Attribution (CC BY) license (https:// creativecommons.org/licenses/by/ $4.0 /)$.

\begin{abstract}
Globally and regionally, there is an increasing impetus to electrify the road transport system. The diversity and complexity of the road transport system pose several challenges to electrification in sectors that have higher energy usage requirements. Electric road systems (ERS) have the potential for a balancing solution. An ERS is not only an engineering project, but it is also an innovation system that is complex and composed of multiple stakeholders, requiring an interdisciplinary means of aligning problems, relations, and solutions. This study looked to determine the political, economic, social, and technical (PEST) factors by actively engaging UK stakeholders through online in-depth and semi-structured discussions. The focus is on dynamic wireless power transfer (DWPT) due to its wider market reach and on the basis that a comprehensive review of the literature indicated that the current focus is on the technical challenges and hence there is a gap in the knowledge around application requirements, which is necessary if society is to achieve its goals of electrification and GHG reduction. Qualitative analysis was undertaken to identify factors that are critical to the success of a DWPT system. The outcome of this study is knowledge of the factors that determine the function and market acceptance of DWPT. These factors can be grouped into six categories: vehicle, journey, infrastructure, economic, traffic and behaviour. These factors, the associated probability distributions attributable to these factors and the relations between them (logic functions), will form the basis for decision making when implementing DWPT as part of the wider UK electric vehicle charging infrastructure and hence support the ambition to electrify all road transport. The results will make a significant contribution to the emerging knowledge base on ERS and specifically DWPT.
\end{abstract}

Keywords: dynamic wireless power transfer; EV charging infrastructure; stakeholder engagement; electric road systems; system demand

\section{Introduction}

There is a drive to increase the pace of electrification of the vehicle fleet in response to global and national policy objectives [1,2]. Improvements in technology, user education, new business models, etc., are all supporting the rapid transition to electric vehicle technology. The challenge is that the road transport system is far from a homogenous entity. Those sectors of the road transport ecosystem that have high energy requirements and/or high use intensity are negatively impacted by the transition to electrification-whilst battery technology is progressing rapidly, the amount of energy that can be stored is still limited compared to existing fuel types [3]. Hence, it is increasingly being recognised that innovation in the charging infrastructure will be the key enabler towards wider electrification. Electric road systems (ERSs) that allow charging on the move, thereby overcoming the inherent limitations of the battery as an energy storage medium, are one innovation. 
Electric road systems is a term that covers a broad range of solutions, including catenary systems, conductive tracks and inductive tracks. Whilst there is an advantage to these systems, their role in a transport system is unclear-the current focus of the research activity is responding to the technical challenges and whether they supplant or complement existing solutions or establish new, yet to be identified niches is an underresearched area. What is clear is that concurrent developments in static charging are reducing vehicle downtime during recharging, whilst developments in battery technology and a reduction in cost are both contributing to improvements in vehicle uptime, thereby negating the need for ERS or, more appropriately, limiting its market potential. To be successful, an ERS will need to provide a valuable contribution to the current vehicle charging ecosystem. This value will be based not only on the technology, but on how that technology meets the stakeholder requirements across a broad range of criteria that may include targeting a specific cost-point, increasing convenience or meeting other, yet to be determined, utility functions.

The purpose of the research reported in this paper is to determine the factors that would contribute to the success of an ERS, specifically a dynamic inductive charging system from a social-technical perspective-as these systems have a wider market reach compared to alternative ERS solutions [4] and is an under-researched area based on the literature. The approach adopted to achieve this was to engage with the stakeholder community within the UK. The following sections provide: a background to the challenge associated with road transport electrification and a basis for the research question (Sections 1 and 2); the approach adopted in this research (Section 3); the results (Section 4); and the interpretation of those results and what they may mean for inductive charging system development (Section 5). This is the first stakeholder engagement of its kind undertaken in the UK that brings together viewpoints of a veritable and diverse group of attendees.

\section{Background}

Climate change is defined as the long-term alteration of temperature and weather patterns. There is robust evidence which indicates a consistent relationship between the cumulative greenhouse gas (GHG) emissions and projected increase in global temperature of between $1.5^{\circ} \mathrm{C}$ and $2{ }^{\circ} \mathrm{C}$ above pre-industrial levels by the year 2100 [5]. Regional and local impacts of global warming are already seen as a consequence of the increase in GHG emissions. There is a strong concern that these impacts will worsen with stronger future climate change [6].

The Paris Agreement, which came into force in November 2016, commits developed and developing countries to keeping global warming below $2{ }^{\circ} \mathrm{C}$ and aspiring to a target of $1.5^{\circ} \mathrm{C}$ [7]. According to the emissions gap report prepared by the United Nations Environment Programme (UNEP) in 2019, the total GHG emissions in 2018 amounted to $55.3 \mathrm{GtCO}_{2} \mathrm{e}$, of which $37.5 \mathrm{GtCO}_{2}$ was attributed to $\mathrm{CO}_{2}$ emissions from the combustion of fossil fuels [8]. Hence, in tackling climate change, current efforts are primarily focused on reducing $\mathrm{CO}_{2}$ and cover technologies and techniques that are deployed in four main sectors, power on the supply side and industry, transportation and buildings on the demand side. However, according to the recent UNEP report referred to above, even if all unconditional nationally determined contributions (NDCs) under the Paris Agreement were implemented, we are still on course for a $3.2^{\circ} \mathrm{C}$ temperature rise. Further and immediate action is therefore required to combat climate change.

Of the four sectors mentioned, it is the transport sector that presents the greatest opportunity to respond. Taking the EU-27 as an example, transport-based on 2018 figures-accounts for almost a third of all $\mathrm{CO}_{2}$ emissions, with road transport responsible for more than two-thirds of the transport related emissions $[9,10]$. Further, $\mathrm{CO}_{2}$ emissions from road transport have increased by a factor of around 1.3 between the 1990 baseline and the most recent, 2019 figures. This compares to the decrease achieved in other sectors (see Figure 1). However, transport as a sector, which is highly reliant on fossil fuels, is perhaps also one of the most challenging to decarbonise [11]. 


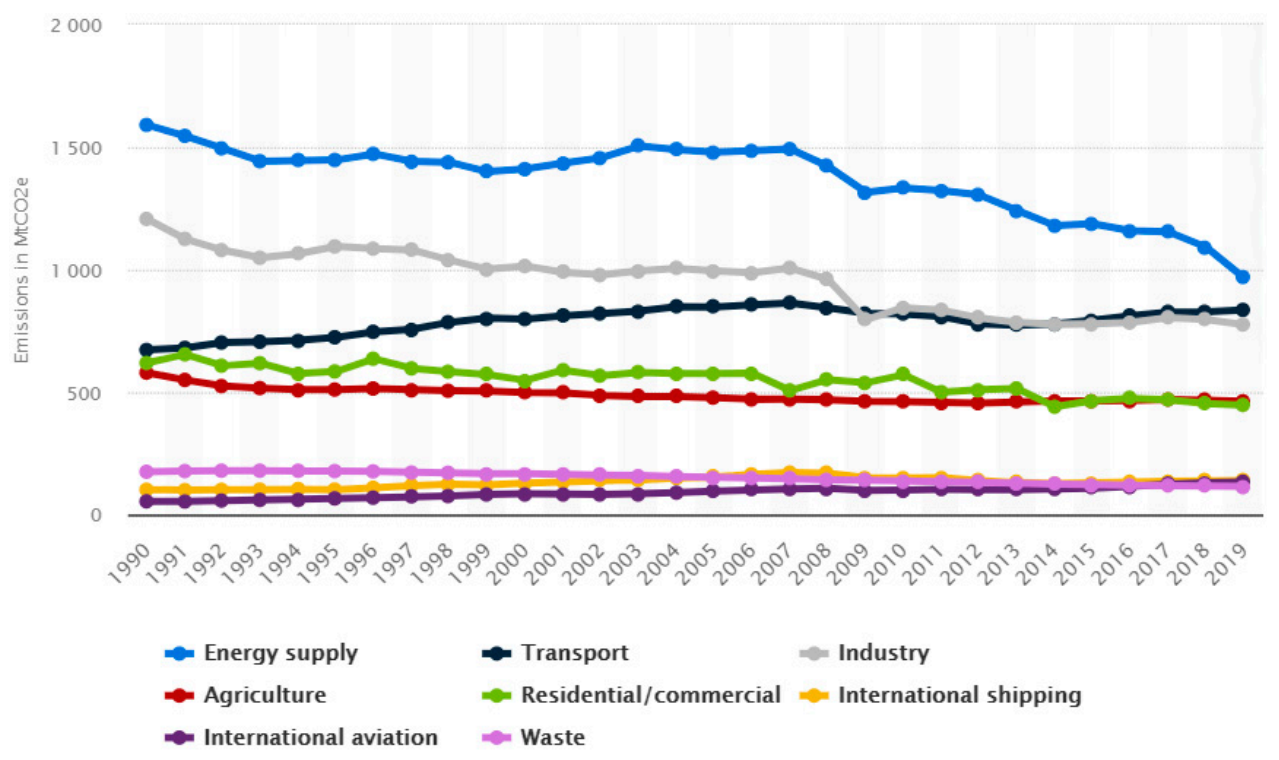

Figure 1. Annual greenhouse gas emissions in the European Union from 1990 to 2019, by sector (in million metric tons of $\mathrm{CO}_{2}$-equivalent) [12].

The most attractive option for decarbonising the road transport sector is electrification, a market-ready technology alternative to the internal combustion engine [13]. Hence, as part of the UK commitment to net-zero GHG emissions by 2050 [14], the UK government has committed to ending "the sale of all new conventional petrol and diesel cars and vans", initially by 2040, but subsequently revised to 2035 and most recently to 2030 [15]. However, in order to achieve the net-zero goal, all road vehicles, including heavy-duty vehicles (HDVs), will need to be entirely decarbonised. Therefore, the UK Government has also announced its intention to consult on a similar phase-out to that planned for cars and vans but targeting diesel-powered heavy-goods vehicles [16].

The UK's ambitious plans to electrify its road transport fleet requires solutions that will reduce cost and drive up consumer confidence. Volume production of batteries, together with manufacturers targeting an increase in the energy density of batteries, has the potential to increase the driving range and at the same time provide a reduction in the cost of electric vehicles. The Automotive Council in the UK commissioned a roadmap on energy storage systems [17]. This roadmap targets a cost saving of around US $\$ 80$ per $\mathrm{kWh}$ between 2017 and 2035. During the same period, it also targets the energy density to double from $250 \mathrm{Wh} \mathrm{kg}^{-1}$ to $500 \mathrm{Wh} \mathrm{kg}^{-1}$. Further, the UK is pressing ahead with the rollout of charging infrastructure to support the electric vehicle user-both a rapid charging network to support users as they move about the UK, but also workplace and home charging solutions to support commuters and shoppers $[18,19]$. In addition, there is also the consideration of subsidies that either reduce cost or make available preferential access to road infrastructure including toll roads, city centres and parking [20]. However, these incentives are likely to prove unsustainable in the long term, requiring a focus on vehicle and charging technologies [21].

As energy storage costs are reducing, and technology is improving, this is encouraging OEMs to increase the battery capacity in their vehicles. What was fast charging for 16-24 kWh batteries becomes not-so-fast when the battery size reaches 40,60 or more $\mathrm{kWh}$. Further, there will also be a requirement, if we are to decarbonise all road transport sectors, to focus on public high-power charging infrastructure in support of regional and long-haul freight operations along the trunk road network. Hence, to meet the expectations of the e-mobility stakeholders and drivers, charge head providers, such as CHAdeMO, are working on higher power charging. A new edition of CHAdeMO protocol enabling $200 \mathrm{~kW}$ to $400 \mathrm{~kW}$ charging was developed by the Association and its members, who are now 
preparing for up to $900 \mathrm{~kW}$ [20]. Similar increases in charging capability are a feature of the EU's CCS system and CharIN is investigating versions up to $2 \mathrm{MW}$ for electric trucks [21]. One potential challenge that the next generation of static charging technology faces is the integration of the charging stations into the existing electricity distribution grid. Recharging times are primarily becoming constrained by the electricity distribution infrastructure and not the technology of the charger/battery combination. Grid capacity is, therefore, a major issue impacting vehicle electrification and market appeal. The most obvious problem is the load increase, which can lead to a system overload since the components like transformers and supply lines are not designed to handle the extra loads requiring investment in reinforcement [22]. This leads to a juxtaposition, whereby the vehicle, through a combination of technology improvement and cost reduction has improved capability but places a requirement upon the charging system to make higher investments that need to be recouped from the system user. This tends to limit the geographical coverage of improved charging systems to where the initial investment can be recouped from higher demand or, conversely a higher operating cost for the system user.

The transition to electrification of road transport is further complicated by the diversity of different vehicle types and use cases. There is a relationship between the energy requirements of a specific modality and use case, and the ability to store energy on and transfer energy to the vehicle. Even with the development in battery technology and the reduction in cost through volume production, the difference that remains vis-à-vis fossil fuels means that replacement with electrification is not suitable for all sectors unless the frequency of charging events is substantially increased-to overcome the limitations upon on-board energy storage - and that those charging events are reduced in duration-the energy transfer rate is substantially increased in order to limit downtime, i.e., when the vehicle is stationary. As such, a transportation system based around the EV, and encompassing all possible modalities and use cases, would require the deployment of an electric refuelling infrastructure far in excess of the current fossil fuel refuelling infrastructure in order to address the driving range and recharging time limitations. These limitations have led to the discussion and exploration of various bespoke charging solutions for specific modalities and use cases, for example, the electrification of the PSV fleet in Eindhoven NL [23]

"Recharging takes place at Hermes' depot via a wireless pantograph system on the roof of each bus. There are 20 rapid chargers for use during the day, 22 slow chargers for use during the night and 2 mobile chargers for the workshop. Alternating rapid and slow charging keeps the batteries in optimum condition. The 43 buses are used on 7 premium public transport bus line services and run at a frequency of 8 to 14 buses an hour. Eventually, 203 electric buses will be put into operation."

Another example is commercial drivers, and specifically taxi drivers, where these barriers are more pronounced as a result of the longer distances covered compared to regular cars, and fewer opportunities for recharging. Results from a recent study [24] indicated that the current plug-in charging infrastructure does not facilitate charging opportunities for taxi trade, causing longer working hours lower earnings. Drivers reported running on a range extender petrol engine once the battery is depleted, limiting the environmental benefits of electric taxis. It was concluded that alternative charger systems, including wireless, could facilitate the increased driving range of existing electric taxis by encouraging opportunistic, short but frequent charging boosts [24].

Electric road systems (ERS) are an alternative set of charging solutions that have the potential to allow electric vehicles to drive longer distances on a single at base charge, without the need to increase battery sizes or to stress the distribution grid unnecessarily. ERS have a long history and encompass in-road wireless, in-road conductive, overhead catenary, etc. A number of studies have explored the concept of the electric road, but the focus has been primarily from a technical and use case point of view [25-29]. It is considered in these studies that it is unlikely that these systems will replace existing 
charging systems but more likely complement (as for the PSV Eindhoven example, we create a charging ecosystem).

The most notable work concerning DWPT includes systems developed by the Korea Advanced Institute of Science and Technology (KAIST), Bombardier and Qualcomm. Other systems include the SIVETEC static WPT system developed by Siemens and the market-ready WiTricity static WPT system initially developed at Massachusetts Institute of Technology. DWPT has the potential to contribute to reducing the weight and the cost of those electric vehicles that have higher energy requirements and/or higher use intensity e.g., heavy goods vehicles or public service vehicles.

For DWPT to become a critical component of the charging ecosystem, a variety of technical challenges must be overcome. Appendix A illustrates how much existing research in the field has focused on debates surrounding technological issues. For example, Hutchinson et al. (2017) consider the technical practicalities of DWPT, whilst Gil and Taiber (2014) assessed the infrastructure challenges of introducing this technology. However, there is a lack of research into the electric road system as a whole. There is a requirement to look at the technical challenges in light of how this system is likely to be deployed and accepted by the user community.

The question that has to be asked is, what is the optimal configuration for successful integration of an electric road system as part of a wider charging ecosystem? The challenge is identifying the criteria that determine the success or limitations of DWPT and any dependencies that may exist between them. As there are multiple types of ERS, each having its associated strengths and weaknesses, the approach was to focus on the in-road dynamic wireless power transfer (DWPT) as this technology has strong adoption potential due to the ability to service multiple use cases-in-road DWPT has the potential to be deployed in multiple roadways (from urban to peri-urban through to motorway) and to service a wide range of different vehicle types (from passenger cars to public service vehicles and through to heavy goods vehicles) [4].

\section{Material and Methods}

The purpose of the research was to identify the factors deemed to have a significant impact on the utility and function of a DWPT system. In order to collect user and stakeholder data, a morning workshop followed by focus groups in the afternoon was organised. An approach was adopted that used the PEST framework in combination with semi-structured discussions was supported by a review of the appropriate literature in the area of DWPT and ERS. These concepts are explained below:

I. The PEST framework has been developed and proven to be successful in exploring the macro-environment $[13,30]$. The PEST framework (PEST referring to the political, economic, societal and technology forces present in the system) was therefore adopted as part of the research activity. PEST assesses a market (including competitors) from the viewpoint of a particular technological proposition or business. In this case the DWPT approach within the ERS is utilised as an addition to the existing market-deployed charging solutions.

II. Semi-structured discussion (that is qualitative/informal conversational/guided approach) seeks to achieve the same level of knowledge and understanding possessed by the respondent and to understand personal experiences and perceptions within a contextualised social framework [31]. In-depth and semi-structured discussions attempt to uncover underlying motives, prejudices, or attitudes towards sensitive issues.

III. A rapid review of the literature was undertaken as a time-limited and resourceefficient approach that provided relevant evidence in support of the analysis step.

By combining the PEST framework, semi-structured discussion and a rapid review of the literature, the purpose was to develop a comprehensive understanding and mapping of the macro-environment into which DWPT is to be deployed. Through this, the significant factors that would determine the success of a DWPT system could be extracted and a 
taxonomy or classification of the significant factors generated. The process followed a number of discrete steps that are outlined below:

\subsection{Stakeholder Selection}

The goal was to get the deepest possible understanding of the setting being studied. This required identification of participants who could provide information about the particular topic and setting being studied. The stakeholders were selected based on achieving a predetermined number of people from different categories-these categories were aligned to the political, economic, societal and technology forces inherent in the PEST framework. The participants were divided under four categories: Policy, Business, Consumer and Technology. In total there were 38 participants from 20 different organisations, including academia (21\%), transport and highway authorities (37\%), energy providers $(10 \%)$, bus operators $(3 \%)$, solution providers $(21 \%)$ and vehicle manufacturers $(8 \%)$.

\subsection{Discussion}

In this research activity, the adopted approach was to establish focus groups (small discussion groups) with a maximum of four stakeholders together with a group facilitator (to ask the questions and guide the process) and a rapporteur (to record the event). Focus groups enable researchers or facilitators to do most of the things they would during an interview, but with a small group. They enable a better focus on specific issues and interests and can also provide opportunities for the group to do more in-depth questioning and promote interaction - all key attributes relating to the stated research. The focus groups were preceded by the workshop where key speakers on the subject of electric vehicle charging development from a policy, economic, societal and technology perspective (one presentation on each and to all groups followed by open Q\&A). The workshop introduced the current state of the art in order to empower the stakeholders with key knowledge around the subject area and beyond their immediate environs-for example, a policyfocused stakeholder will be aware of the key developments in the technology sector. In general, each of the focus group discussions lasted around $30 \mathrm{~min}$. The discussions were based on the following two broad questions:

Q1. What will be the key determining factors that will support the success or failure of dynamic wireless charging as one of the charging infrastructures options?

Q2. What would be the ideal dynamic wireless charging infrastructure system from your perspective, and how would this be reached?

\subsection{Transcribing}

Post-event, the generated material was prepared for analysis. Qualitative (thematic) analysis of the discussion transcripts was then undertaken to seek patterns, themes and meanings that generate an in-depth understanding of the phenomenon of interest. The qualitative analysis was approached as a critical, reflective and iterative process that cycled between data and the overarching research framework that kept the big picture in mind. This approach has been applied previously for analysing semi-structured interviews [32,33]. The analysis was inherently a process of interpretation. Questions were asked of the data, informed by theory and by observations, hypotheses or hunches. If the analysis was rigorous and transparent, then the data should be able to support or not support these. This is the important part- the data needed to support or refute our ideas and should not fit the data into the story we want to tell $[34,35]$.

\subsection{Analysis}

There were two parts to analysing the data, and these were as follows:

- "Content analysis" steps: read transcripts > highlight quotes and note why important $>$ code quotes according to margin notes; and

- "Exploration analysis" steps: sort quotes into coded groups (themes) $>$ interpret patterns in quotes $>$ describe these patterns. 
The last step in the methodology was to verify and report the results of the analysis. Verifying related to the 'reliability' (how consistent the results were) and 'validity' (whether the study investigated what was intended to be investigated) of the data. Verification was undertaken by comparing and contrasting the results of the analyses across the needs of electric vehicle charging infrastructure (as determined from the background section and supported as appropriate by the rapid review of the literature).

\section{Results}

The focus group discussions covered a multitude of topics, including the status of the EV, consumer behaviour, potential users, EV charging technologies, grid and transport network implications and policy and standards requisites that fit within the two broad questions. The following section reports on the core points that were discussed in the focus groups.

\subsection{Policy}

The section discusses the views of those stakeholders with a background in the development and/or delivery of policy, especially stakeholders who would have a future role in creating and managing the policy environment around DWPT.

Cost: Developing dynamic wireless charging infrastructure requires a high capital cost; therefore, "an attractive business case is required" to convince potential private or public investors who may perceive the return of investment on the technology to be uncertain, at least in the short to medium term. Since DWPT is relatively a new technology, scarcity in data availability can be a challenge for policymakers to develop business cases. Pilot studies such as DynaCov were recognised as essential to collect the necessary data. The importance of accounting for future EV landscape and user needs while developing the business case was stressed.

Infrastructure location: Selecting the right location for the infrastructure is crucial for success. It was commented that the dynamic wireless charging solutions (DWCS) must complement the other existing charging facilities and fully integrate with the charging ecosystem within the area. Furthermore, to compete with other charging solutions, the charging cost to the user must be attractive. One way to manage the cost to the user is by encouraging competition within the dynamic charging market. The road selected for the infrastructure must not possess any significant constraint for installing the infrastructure. It was noted that it might be more feasible to electrify roads within strategic road networks, including motorways and primary roads. In general, these road networks "are well maintained and contain space for installing required utilities". Moreover, these roads have a higher chance of carrying the required number of target vehicle types and volumes.

Temporal considerations: The disruption that may be caused during the construction phase can be detrimental to the success of the solution. It has the potential to disenfranchise the user. Therefore, installations "must be done over a relatively short period in terms of road closures". Furthermore, the implications of the solution for the existing road utilities and that may be installed in the future was emphasised to be evaluated. However, it was agreed that futureproofing for all needs could "significantly increase the solution's design and the implementation cost".

User Considerations: It was highlighted that the on-road charging solution must cater to different types of vehicles and users. However, there was a broader consensus that the DWCS will be more suited for commercial users who drive long distances and fixed routes. Private owners who usually drive fewer miles in a day are "more likely to use home charging or destination charging facilities". Changing consumer's behaviour was ranked as one of the main challenges for the successful adoption of this charging solution. Public engagement activities are suggested to be vital for promoting the technology. Furthermore, "acceptance of the technology by vehicle manufacturers is essential" to gain confidence among potential users, especially as this technology requires fixing additional components to the vehicle. Empowering the user is essential; "the ultimate decision to use the charging facility must be with 
the user". A transparent pricing plan and a payment solution that is safe, secure and easy to use are necessary. For a better user experience, it was suggested that the payment solution should be integrated with other charging infrastructure providers within the region.

\subsection{Consumer}

The section discusses the views of those stakeholders that have a background in the use cases that are developed around charging infrastructure, especially stakeholders who would have a future role in determining how DWPT is likely to be used via actions that include the purchase of vehicles that are DWPT compliant.

Capital Cost (Provider): The importance of public charging facilities will remain highly relevant for the uptake of electric vehicles. The DWPT has the potential to "relieve pressure on the number of charge heads (rapid static charging)" that are required to meet future demand. The fear and anxiety among users to adopt a relatively new charging solution may affect the uptake of the DWCS. The users might as well think, "if costs are coming down in 5-10 years, why invest now"? Similarly, potential users may be concerned about the emergence of hydrogen-based fuels as a preferred solution for buses and heavy goods vehicles, which is the main target vehicle types for this technology. Therefore, stakeholders' acceptance of the product, proving the technology's longevity, and policies by the central and regional governments supporting DWCS were identified as critical factors to increase the user base.

User Behaviour: The transport pattern within the target infrastructure location drives the use of the facility. The distribution of vehicle types, user types, traffic flow, battery capacity, state of charge (SoC) thresholds, and the number of miles covered in a day by a given vehicle type are key variables that impact the charging decision-making. Similarly, the driver's range anxiety influences the decision-making for using the charging infrastructure. Smart battery management solutions are required to help make a manual or automated decision to maintain the necessary level of SoC.

Capital Cost (User): The market for the DWPT technology would be driven by commercial users who cover longer distances or consume higher levels of energy such as "public transport services (taxies, buses and coaches), last-mile delivery and haulage companies". Dynamic wireless charging may also provide an option for businesses to purchase smaller electric vehicles (like the Renault Zoe), which are usually cheap. However, the range of those vehicles could be increased using this charging solution. Commercial users are generally cost-sensitive; therefore, there is a need for the solution to be cost-effective compared to other vehicle charging types. Furthermore, the business customers expect the technology to integrate easily with their system without causing any operational constraints. Dynamic wireless charging can help lower the vehicle cost by reducing the size of the battery pack. In addition, a reduction in battery size may improve the vehicles' energy consumption and utility capacity. For example, it was commented that "for a double-decker bus, we (a large-scale national coach operator) lost about two pairs of seating capacity because of the extra space required for the batteries". Considering the advantages, a commercial user may opt for "re-specifying the vehicles based on the availability of the dynamic charging facility along the routes."

Operational Cost User: As the adoption of EVs equipped with DWPT technology grows, the challenges placed upon the power grid are most likely to increase. There is a clear interaction between the traffic pattern and demand on the grid from vehicles. Smart pricing strategies are essential to relieve the pressure on the grid during the peak power consumption period. For example, "the cost to access the charging facility could be increased at peak times". However, it was also suggested that the variable pricing might not be attractive to commercial users who may prefer to know the energy cost in advance for estimating their operation cost. Therefore, an arrangement is necessary between potential largescale commercial users and the solution provider. 


\subsection{Business}

The section discusses the views of those stakeholders that have a background in the development and/or operation of business models around DWPT, especially stakeholders who would have a future role in managing the deployment and assessment management of a DWPT solution.

User Engagement: Standardisation of the technology is vital; ensuring that the technology is compatible with different vehicle types is important to the user base. Business users are expected to be the main DWPT consumers. Therefore, the primary business model for this charging solution was predicted to be "business-to-business rather than business-toconsumer". Local councils who generally operate large fleets, and public road infrastructure, transport services, freight and delivery businesses are identified as target business customers. Public engagement can help to spread knowledge and awareness about this relatively new technology. Tools such as advertisement signage and outreach campaigns can inform users about the technology and its benefits.

User Behaviour: Retrofitting the receiver and other essential components must not affect the vehicle's appearance, which is common among private vehicle owners. It was commented that the involvement of vehicle manufacturers in the designing of the receiver system installation is required. Charging the vehicle on the go may influence driving behaviour. In general, DWPTs "incentivise travelling slowly"; hence drivers may prefer altering their driving behaviour. Its impact on the traffic flow must be evaluated. The amount of charge a vehicle can receive depends on various external factors such as the power quality, traffic speed, and power drawn by other vehicles aligned with the same coil segment. This variability in charging may reduce user's confidence in the technology. Therefore, it is necessary to overcome this challenge with a system that could pre-inform the user about the expected amount of charging. This scenario is more relevant in an urban setting where vehicles travel bumper to bumper during peak hours.

\subsection{Technology}

The section discusses the views of those stakeholders with a background in the development of the underlying technology, especially stakeholders who would have a future role in supplying DWPT solutions into the marketplace.

Stakeholder Communities: Effective communication between different stakeholders, including road and grid operators, utility providers, transport authorities and local governments, is crucial for the smooth operation of the DWPT infrastructure. The development of tailored technological solutions such as an in-vehicle interface to commence and end charging, over-the-air software or firmware updates, and smart payment systems are essential for a better user experience.

Product Standards: The requirement for standards specifically designed to address technical and safety aspects of DWPT methods are vital for the successful commercialisation of the technology. Any potential health and safety concerns related to electromagnetic fields (EMF) and electromagnetic compatibility (EMC) issues associated with the technology must be addressed. For example, "leakage of magnetic fields must not interfere with a person's health monitoring devices", like pacemakers. Similarly, the magnetic field generated by the system "must not interact with communications devices" used by emergency teams, maintenance teams and any other local key infrastructures such as airports. It is also important that when a vehicle passes over a specific segment, only that segment is activated and transmit energy to the receiver on that vehicle to avoid any risk to other nearby motorists and pedestrians using the roadway. This suggests a need for the "development of a detailed safety case" covering all risks, hazards and mitigation plans before deployment of the solution.

Performance Improvements: The power transfer efficiency of the system is affected by an air gap and lateral misalignment between the transmitters and receivers. It was noted that information and communication-based technology "may be required to inform the driver to make the necessary correction" to improve the coupling efficiency. 
Performance Management: The connection of a large number of electric vehicles that arrive at different times and travel at different speeds can create varying power demand patterns upon the grid, raising power quality issues such as the injection of harmonic currents. To mitigate this, "appropriate roadside power electronics are necessary". Moreover, DWCS may further load the grid during its peak demand period if it coincides with the charging facility's peak usage period. Therefore, "future planning of the grid power supply is necessary". Furthermore, the impact of the DWCS on the local traffic pattern should be thoroughly evaluated.

\section{Discussion}

The study reconfirmed several factors, including a number of challenges that support the success and potential benefits of the DWPT system. The deployment of appropriate charging infrastructure is deemed a prerequisite for the wider uptake of EVs. Several charging infrastructure solutions are being installed across the country, such as rapid chargers, fast chargers and slow chargers [36]. They form a charging ecosystem that responds to the requirements for destination and opportunity charging. The success of the DWPT charging infrastructure will ultimately be based on the number and type of users if the initial costs are to be sufficiently amortised. The participants mentioned that the initial deployment scenarios need to maximise the usage of the technology. The commercial users who drive long distances on fixed repeatable routes are suggested as initial target users. This is supported by the literature, with Meijer [37] suggesting the deployment of DWPT systems along urban bus routes as well as short and long haul national and international freight corridors.

In order to create stakeholder acceptance of DWPT charging infrastructure, it is necessary to predict the energy demand from the EVs that potentially use the facility. From the focus group transcripts, and supported by the literature, key externalities were identified, and these externalities were classified into a taxonomy consisting of six categories:

I. Vehicle: these externalities determine whether a vehicle will make a request to charge based on factors attributable to the vehicle condition, e.g., the current SoC of the battery.

II. Journey: these externalities determine whether a user will make a request to charge based on the specific mission, e.g., during the journey, the driver can actively extend the battery range based on the journey requirement.

III. Behaviour: these externalities determine the type of charge that will result, e.g., along a fixed length of charging infrastructure, the speed of the vehicle will determine the energy transferred.

IV. Economic: these externalities determine whether a charge will be requested based on the economic considerations and alternatives, e.g., the cost to access or the cost per unit of energy.

V. Traffic: these externalities determine the demand upon the DWPT system that will result from external factors, e.g., the density and mix of traffic that flows across the system.

VI. Infrastructure: these externalities determine the broader user choice to adopt DWPT based on the availability of the system both geographically and capability, e.g., is it available on the route options for the user.

The externalities noted above are factors that will affect the uptake of DWPT either positively or negatively, and it is the combination of these factors that is important in defining demand. Figure 2 shows the taxonomy generated from the analysis of the focusgroup transcripts and how the factors combine to determine demand. The structure of the taxonomy is derived from the analysis of the focus group discussions. Its relation to the published literature is discussed in the following section. 


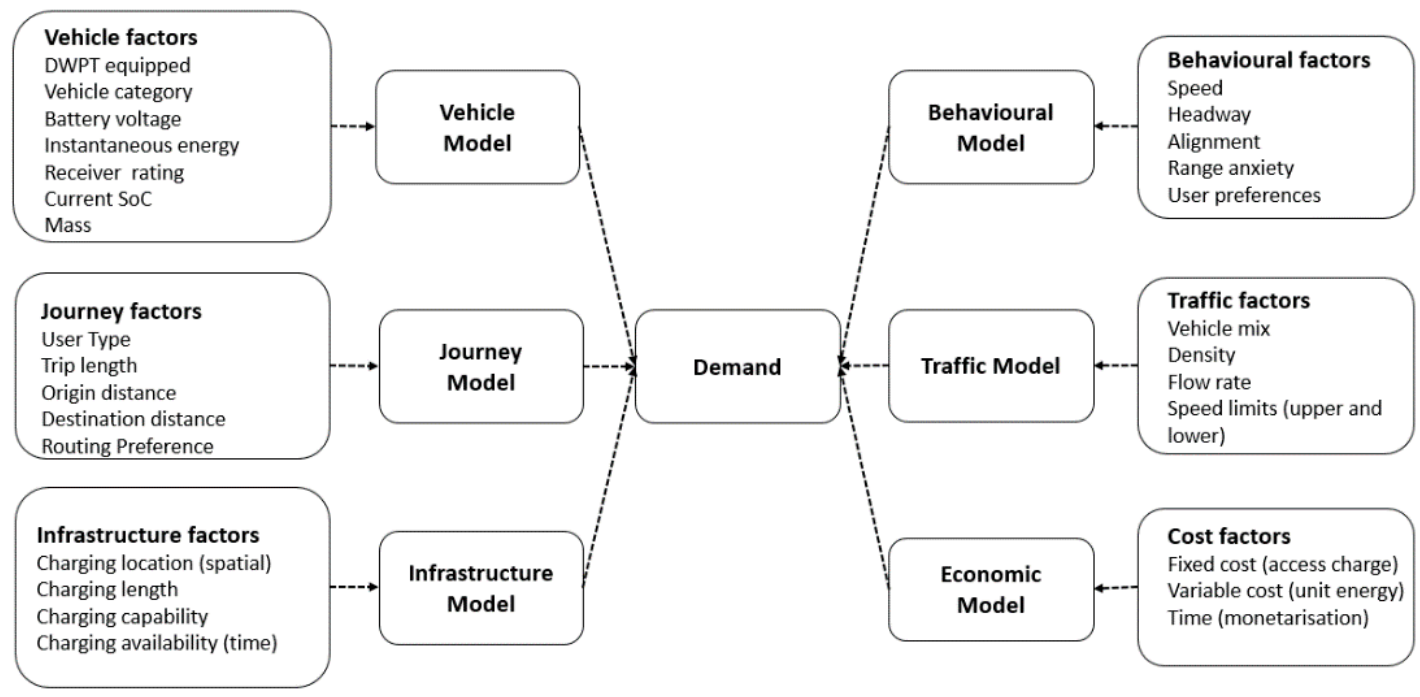

Figure 2. Taxonomy-linking Factors identified from focus groups to demand.

The focus group participants mentioned that the EV drivers are usually sensitive to costs associated with charging, concurring with previous studies [38-42]. Two concerns arose regarding cost. One was the investment cost and the recognition that, in order to mitigate the high investment cost of DWPT being passed on to the users, supportive government policies and financial subsidies, and incentives would be essential for wider uptake of the charging infrastructure, again concurring with existing studies [41]. Second was that the focus group suggested that EV users' charging behaviour is influenced by cost-driven factors such as (a) the actual cost to charge and (b) the impact of the charging method on operational efficiency. It is recognised in the literature that the actual cost to charge includes one or more components such as access fee, a kWh-based charge, usually varying with the time of use (ToU) and payment processing fees [42]. Studies have shown that smart pricing strategies based on ToU can shift charging to the off-peak period that is beneficial to the grid and, most consumers have been willing to accept this costing method. However, there is a lack of uncertainty in the willingness to use smart charging schemes between private and commercial users. Unlike static charging solutions, DWPT allows a vehicle to charge while in motion, avoiding financial losses that may be incurred due to vehicle downtime associated with stationary charging solutions. Indeed, Oliveira et al. (2020) [24] concluded that taxi drivers are more likely to lose earnings due to charging time associated with wired solutions. Furthermore, time-sensitive services like freight and public transport systems may not have enough time to get the required energy with stationary solutions $[43,44]$. By reducing the vehicle downtime owing to charging stops, dynamic wireless charging can be an effective solution in such scenarios [45].

Batteries constitute a significant proportion of the EV cost [46]. DWPT offers the opportunity to reduce the battery size whilst reducing vehicle cost, increasing range, and vehicle's utility (for example, capacity). Participants were also concerned about the costs associated with installing the hardware and software that are required for DWPT charging. The participants mentioned that customers expect these costs to be recouped either with a low charging price or improved operational efficiency. A similar opinion was reported in Oliveira et al. (2020) [24].

The focus group discussions suggested that the use case for the DWPT infrastructure has interdependencies with factors relating to journeys undertaken by the users, such as origin and destination of the trip, purpose of the trip and routing preference. The EV users who generally drive fewer miles than the battery range prefer destination charging at home or work [38]. Private EV users generally fall in this category. On the other hand, long-distance and energy-intensive operations such as freight and public transport services such as buses, coaches and taxis require public charging solutions at different locations. 
Moreover, fixed-route services such as buses and coaches cannot detour; therefore, they rely on charging facilities along the route in addition to the infrastructure within the depots $[45,47]$. In general, these journey-related factors influence the willingness to alter the route for accessing a charging solution. Philipsen et al. (2015) [48] reported that users are more willing to accept a detour of $5 \mathrm{~km}$ or $10 \mathrm{~min}$ to a fast-charging station. Furthermore, Philipsen et al. (2016) [49] indicate that participants prefer to make a detour rather than accept waiting times for charging.

The participants mentioned that the design of the system needs to be interoperable, catering for a wider type of vehicle and operating conditions. However, a challenge is that there are several factors relating to vehicle characteristics as well as the technology and type of the charging system that affect the energy demand of an EV. Battery capacity is a primary factor that determines the range of an EV. A larger battery capacity enables the vehicle to travel longer distances. Therefore, when faced with a specific journey requirement, they may seek fewer charging opportunities than vehicles with smaller battery capacities. Previous research found SoC to be a key factor that determines the energy demand of an EV during a charging event. It is well recognised that specific real energy consumption that determines the $\mathrm{SoC}$ depends on several parameters, including battery temperature, utilisation of in-vehicle systems such as heating and ventilation, vehicle load, vehicle acceleration/deceleration, rolling friction, aerodynamic drag, and road gradient. Mishra (2018) [50] recommends operating EV batteries within a threshold range rather than taking advantage of the full range between $0 \%$ and $100 \%$. For Li-ion batteries, the optimum SoC area is determined to be between $20 \%$ and $80 \%$. Maintaining SoC at these levels reduces the rate of battery degradation and expands operation lifetime. Respecting the $\mathrm{SoC}$ range is essential; however, a driver or fleet owner may choose to operate outside this range.

A particular challenge is to develop a DWPT system capable of higher power transfer efficiencies with a wider range of lateral and vertical misalignments (air gap) between the primary source coils embedded within the road and secondary on-board coils (receiver) [51]. Naberezhnykh [52] recommends the system design to consider driver lateral misalignment of up to $15 \mathrm{~cm}$ for optimum usage of the charging system. The power transfer efficiency is shown to drop gradually as vertical misalignment grows [28]. Further, the air gap differs with the vehicle type, and it can vary with the loading conditions. The speed of the vehicle is expected to affect the power transfer efficiency. With an increase in the vehicle speed, the interaction time between the primary and secondary coils reduces, resulting in lower power transfer efficiency [52]. Other vehicle characteristics such as mass and vehicle length affect the energy demand of EVs. Further simulation and/or demonstrator work is required to demonstrate the relationship between the vehicle speeds and power transfer efficiencies. Heavier vehicles require more mechanical power, consuming higher energy. Vehicle type (length) determines the maximum number of vehicles in a section. It also influences the number of secondary coils (receivers) that can be fitted to the vehicle.

These findings reiterate the need for standardisation of DWPT systems and associated technologies to ensure that the deployed systems are safe, efficient and interoperable. Furthermore, standards allow manufacturers to develop and optimise their systems to the infrastructure [52]. Several organisations such as the International Organisation for Standardisation (ISO), International Electrotechnical Commission (IEC), and Society of Automotive Engineers (SAE) are currently developing standards related to DWPT, irrespective of the barriers faced due to the technical complexity and current level of maturity of the technology [53].

Studies have shown that charging behaviour is heterogeneous [54,55] among drivers. In general, factors including range anxiety, user comfort and other individual preferences contribute to charging decision making [39]. Range anxiety among EV users is a psychological barrier that can be induced by insufficient range to reach a destination or complete daily trips within a stipulated time, associated with the time required for charging and charger location. An EV driver with a higher level of range anxiety may access a charging facility when the SoC is higher than the recommended threshold. Furthermore, a higher 
level of range anxiety can potentially lead to dangerous driving behaviour and negatively affect drivers' emotions. As the driver's experience with the EV increases, the driver may correctly predict the EV's range concerning their range requirements, thus reducing the range anxiety [56]. The focus group participants mentioned that an in-vehicle system capable of providing a real-time charging recommendation for the driver could be helpful to overcome this challenge [57].

The participants raised issues concerning willingness to adapt driving style to suit the traffic and improve charging efficiency. The alterations to normal driving behaviour may cause inconvenience to drivers and affect their charging decision making. For example, whilst accessing the charging lane, the driver may not be able to overtake other vehicles and need to drive within a specific speed range. In addition, the driver may need to maintain distance with the leading vehicle (headway) and vehicle alignment, which can be challenging even for an experienced driver [37]. Yang and Lu (2018) [56] acknowledged that it is necessary to account for these behavioural and psychological factors for a successful mass adaptation of EV infrastructure. In those vehicles with advanced driver-assist or automated driving systems, the vehicle's alignment can be controlled by electronic systems, thus improving driver comfort. Further measures such as driver training, road markings, and lane guides can improve charging efficiency and user comfort [42]. However, further user-based research is expected to yield satisfactory measures for users to choose DWPT charging mode.

These categories and factors within the categories can be used to support the development of DWPT. Based on the above discussion, it is recognised that there will be a logical flow that will determine if a charge event takes place, the power demand and the energy that is transferred. The gateway will be the vehicle condition; the capability of the vehicle-if it is equipped with a receiver and the ability to store energy or consume energy - will determine a request to charge and the power transferred. Following this, the journey or mission of the vehicle will determine the probability of a charge event-the longer the journey, the higher energy consumption, etc., the greater the probability of a charge request. This probability will be moderated to an extent by the immediate costbenefit of charging dynamically or statically. As described in the preceding discussion, if a charge event is required, then the choice of how to meet that charge event-static or dynamic -is a complex interplay between access costs, energy cost, monetarisation of time, etc. The behaviour of the user and the traffic environment then determines the transit time-a quicker transit time means less energy transferred, but further, a transit event that is permeated by stop-start traffic will also impact upon energy transfer. Finally, the availability of infrastructure, either geographically_leading to different vehicle routing —or having a cap based on power supply-leading to a limit on vehicles that can be serviced-will impact power levels and energy transfer.

The identified parameters, those that determine the behaviours outlined above, can be further used to estimate demand on the network using simulation modelling techniques, such as the Agent-based model (ABM) or Bayesian network model. An Agent-based model (ABM) is a class of simulation in which a system is modelled as a collection of autonomous decision-making entities called agents that interact with each other, allowing exploration of emerging behaviour of the system, usually difficult to predict in the real world [58]. Bayesian network models are structured based on Bayes' theorem, capable of updating the prior probability of some unknown variable when some evidence describing that variable exists [59].

\section{Limitations}

DWPT is a technology that is uncommon and rapidly evolving; therefore, identifying and inviting participants with specific expertise was difficult. While all efforts were made to invite stakeholders with expertise in different areas relating to DWPT technology and EV charging in general, the findings reported in this study may have insufficient depth in some of the topics. All the attendees were UK based; therefore, the ideas generated might not be 
directly transferable to the rest of the world. However, the study generated a vast amount of relevant knowledge that can form a basis for decision making when implementing this technology to support the transition to electrification within the transport sector.

\section{Conclusions}

In response to policy commitments, there is a requirement to electrify road transport. It is also recognised that road transport is a complex system requiring a range of solutions that include improvement at the vehicle level and innovation in charging infrastructure. One potential innovation is electric road systems (ERS), and specifically, dynamic wireless power transfer (DWPT) due to its wider market appeal relative to alternatives. Implementation of ERS requires that the challenges are identified in order that appropriate solutions can be implemented. One issue is that current techno-centric approaches do not properly consider the complex relationships between organisations, the people enacting business processes and the system that supports these processes.

This research was the first activity to focus on identifying the challenges for DWPT considering the political, economic, societal and technology perspectives and in a UK context. The research successfully brought together 38 key stakeholders and generated over $8 \mathrm{~h}$ of key discussion. A taxonomy of externalities-the factors that impact negatively or positively-relevant to DWPT in the UK context was generated. The taxonomy classified the externalities/factors into six categories.

- Condition of the vehicle-will it accept a charge and what power?

- Journey that is undertake-does the mission require a charge event?

- User behaviour-what will be the type of charge that will result?

- Economics-will there be a cost-benefit to a charge event?

- Level of traffic — what will be the potential energy transferred?

- Infrastructure-what is the availability for a charge event?

The definition of the factors within each category will determine if a charge event occurs and the amount of energy transferred. There will be a clear logical flow, i.e., the condition of the vehicle will be the entry point, the journey will define a need, the economics will define the choice, the infrastructure will define the energy available, the behaviour will modify that energy transfer within limits defined by the traffic. The taxonomy and logic flow will allow for creation of a systems model that will inform the decision-making process of rolling out the DWPT system. The results of this research are supported by the existing literature in this area and form the basis for decision-making when implementing DWPT as part of the wider UK electric vehicle charging infrastructure and hence support the ambition to electrify all road transport. Combined with the factors reported in this study, real-world testing will identify additional parameters that will allow the successful implementation of the DWPT system.

Author Contributions: Formal analysis: K.E., S.G. and H.D., conceptualisation: K.E., H.D. and S.G., methodology: K.E., H.D., S.G. and S.B., data curation: K.E., S.G. and H.D., validation: K.E., S.G. and H.D., resources: H.D. and S.B.; writing—original draft preparation: K.E., S.G. and H.D.; writing-review and editing: K.E., S.G., H.D., S.B. and A.J., supervision: H.D. and S.B., project administration: H.D.; funding acquisition: H.D. and S.G. All authors have read and agreed to the published version of the manuscript.

Funding: The stakeholder event was held as part of Dynamic Wireless Power Transfer, a feasibility study project, led by Coventry City Council and project partners on behalf of Western Power Distribution (WPD) using Network Innovation Allowance (NIA) funding.

Institutional Review Board Statement: The study was conducted in accordance with Coventry University's Ethical Approval process.

Informed Consent Statement: Informed consent was obtained from all subjects involved in the study.

Conflicts of Interest: The authors declare no conflict of interest. 


\section{Appendix A}

Table A1. Summary of literature regarding Dynamic Wireless Power Transfer (DWPT) an electric road system (ERS).

\begin{tabular}{|c|c|c|c|}
\hline Author & Title & Summary & Publication \\
\hline $\begin{array}{l}\text { Hutchinson Luke; } \\
\text { Waterson Ben; Anvari } \\
\text { Bani; Naberezhnykh } \\
\text { Denis } \\
2019\end{array}$ & $\begin{array}{l}\text { Potential of wireless power } \\
\text { transfer for dynamic charging } \\
\text { of electric vehicles }\end{array}$ & $\begin{array}{l}\text { Paper discusses the technicalities of electric } \\
\text { vehicles, dynamic charging infrastructure, } \\
\text { different projects organisations developing WPT } \\
\text { solutions along with ISOs }\end{array}$ & $\begin{array}{l}\text { Journal: IET Intelligent } \\
\text { Transport System } \\
\text { doi:10.1049/iet-its.2018.5221 }\end{array}$ \\
\hline $\begin{array}{l}\text { Jesko Schulte; Henrik } \\
\text { Ny } \\
2018\end{array}$ & $\begin{array}{l}\text { Electric road systems: } \\
\text { Strategic stepping stone on } \\
\text { the way towards sustainable } \\
\text { freight transport? }\end{array}$ & $\begin{array}{l}\text { The paper looks at Electric Road Systems (ERS) in } \\
\text { comparison to the current diesel system. The } \\
\text { Framework for Strategic Sustainable Development } \\
\text { was used to assess whether ERS could be a } \\
\text { stepping stone on the way towards sustainability }\end{array}$ & $\begin{array}{l}\text { MDPI, Sustainability } \\
\text { (Switzerland) } \\
\text { doi:10.3390/su10041148 }\end{array}$ \\
\hline $\begin{array}{l}\text { Francesco Deflorio; } \\
\text { Luca Castello } \\
2017\end{array}$ & $\begin{array}{l}\text { Dynamic } \\
\text { charging-while-driving } \\
\text { systems for freight delivery } \\
\text { services with electric vehicles: } \\
\text { Traffic and energy modelling }\end{array}$ & $\begin{array}{l}\text { This paper develops and implements a specific } \\
\text { traffic model based on a mesoscopic approach, } \\
\text { where energy requirements and charging } \\
\text { opportunities affect driving and traffic behaviours }\end{array}$ & $\begin{array}{l}\text { Transportation Research Part C: } \\
\text { Emerging Technologies } \\
\text { doi:10.1016/j.trc.2017.04.004 }\end{array}$ \\
\hline $\begin{array}{l}\text { Nicolaides Doros; } \\
\text { Cebon David; Miles } \\
\text { John } \\
2019\end{array}$ & $\begin{array}{l}\text { An Urban Charging } \\
\text { Infrastructure for Electric } \\
\text { Road Freight Operations: A } \\
\text { Case Study for } \\
\text { Cambridge UK }\end{array}$ & $\begin{array}{l}\text { This paper investigates the park and ride bus } \\
\text { routes, the refuse collection operations, and two } \\
\text { home delivery operations for } 6 \text { charging } \\
\text { infrastructure for electric road freight operations }\end{array}$ & $\begin{array}{l}\text { IEEE Systems Journal } \\
\text { doi:10.1109/JSYST.2018.2864693 }\end{array}$ \\
\hline $\begin{array}{l}\text { Chen Feng; Taylor } \\
\text { Nathaniel; Kringos } \\
\text { Nicole } \\
2015\end{array}$ & $\begin{array}{l}\text { Electrification of roads: } \\
\text { Opportunities and challenges }\end{array}$ & $\begin{array}{l}\text { This paper presents the historical overview of the } \\
\text { technology development towards the } \\
\text { electrification of road transportation and explores } \\
\text { in more details the Inductive Power Transfer (IPT) } \\
\text { technology }\end{array}$ & $\begin{array}{l}\text { Applied Energy } \\
\text { doi:10.1016/j.apenergy.2015.03.067 }\end{array}$ \\
\hline $\begin{array}{l}\text { Gil A; Taiber J } \\
2014\end{array}$ & $\begin{array}{l}\text { A Literature Review in } \\
\text { Dynamic Wireless Power } \\
\text { Transfer for Electric Vehicles: } \\
\text { Technology and Infrastructure } \\
\text { Integration }\end{array}$ & $\begin{array}{l}\text { This paper presents a literature review on the } \\
\text { advancements of stationary and dynamic wireless } \\
\text { power transfer used for EV charging. addressing } \\
\text { power limitations, electromagnetic interference } \\
\text { regulations, communication issues and } \\
\text { interoperability, in order to point out the } \\
\text { technology challenges to transition from stationary } \\
\text { to dynamic wireless charging and the } \\
\text { implementation challenges in terms } \\
\text { of infrastructure }\end{array}$ & $\begin{array}{l}\text { Springer Link, Sustainable } \\
\text { Automotive Technologies } 2013 \\
\text { doi:10.1007/978-3-319-01884-3_30 }\end{array}$ \\
\hline
\end{tabular}

GPaolo Lazzeroni;

Vincenzo Cirimele;

Aldo Canova

2020

Katsuhiro Hata;

Takehiro Imura;

Yoichi Hori

2016

\section{Tharsis Teoh}

2021
Economic and environmental sustainability of Dynamic Wireless Power Transfer for electric vehicles supporting reduction in local air pollutant emissions

\section{Dynamic wireless power} transfer system for electric vehicles to simplify ground facilities-power control and efficiency maximization on the secondary side

Electric vehicle charging strategies for Urban freight transport: concept and typology
This paper looks at the possible variations of the energy mix and the effects related to the increase in the electric energy demand related to the increase in the circulating electric vehicles.
Renewable and Sustainable

Energy Reviews

doi:10.1016/j.rser.2020.110537

This paper looks at a novel secondary-side control method for power control and efficiency maximization. These control strategies and the controller design proposed are based on the WPT circuit analysis and the power converter model.
This conceptual paper synthesizes the perspectives found in literature on the charging strategy concept, and provides a definition based on Orlikowski's structurational model of technology
IEEE Applied Power Electronics Conference and Exposition (APEC)

doi:10.1109/APEC.2016.7468101

Routledge Taylor \& Francis Group doi:10.1080/01441647.2021.1950233

\section{References}

1. $\quad$ European Commission. EU Launches Clean Fuel Strategy. EU Press Releases, 4 January 2013.

2. Egbue, O.; Long, S. Barriers to Widespread Adoption of Electric Vehicles: An Analysis of Consumer Attitudes and Perceptions. Energy Policy 2012, 48, 717-729. [CrossRef]

3. Balali, Y.; Stegen, S. Review of Energy Storage Systems for Vehicles Based on Technology, Environmental Impacts, and Costs. Renew. Sustain. Energy Rev. 2021, 135, 110185. [CrossRef] 
4. Schulte, J.; Ny, H. Electric Road Systems: Strategic Stepping Stone on the Way towards Sustainable Freight Transport? Sustainability 2018, 10, 1148. [CrossRef]

5. IPCC. Climate Change 2014: Synthesis Report. Contribution; IPCC: Geneva, Switzerland, 2014.

6. Field, C.B.; Barros, V.R. (Eds.) Climate Change 2014-Impacts, Adaptation and Vulnerability: Regional Aspects; Cambridge University Press: Cambridge, UK, 2014. Available online: https://www.ipcc.ch/site/assets/uploads/2018/02/ar5_wgII_spm_en.pdf (accessed on 14 July 2021).

7. Lieven, T. Policy Measures to Promote Electric Mobility-A Global Perspective. Transp. Res. Part A Policy Pract. 2015, 82, 78-93. [CrossRef]

8. UNEP. Emissions Gap Report 2019 Executive Summary. 2019. Available online: https:/ /www.unep.org/emissions-gap-report-20 20 (accessed on 14 July 2021).

9. Indicators-European Environment Agency. Available online: https://www.eea.europa.eu/data-and-maps/indicators/\#c7=all $\& c 5=$ transport\&c0 $=10 \& b \_s t a r t=0$ (accessed on 28 June 2021).

10. EU Transport in Figures: Statistical Pocketbook / Eltis. Available online: https://www.eltis.org/in-brief/facts-figures / eu-transp ort-figures-statistical-pocketbook (accessed on 28 June 2021).

11. Neves, S.A.; Marques, A.C.; Fuinhas, J.A. Is Energy Consumption in the Transport Sector Hampering both Economic Growth and the Reduction of $\mathrm{CO}_{2}$ Emissions? A Disaggregated Energy Consumption Analysis. Transp. Policy 2017, 59, 64-70. [CrossRef]

12. Nilsson, M.; Nykvist, B. Governing the Electric Vehicle Transition-Near Term Interventions to Support a Green Energy Economy. Appl. Energy 2016, 179, 1360-1371. [CrossRef]

13. Davies, H.; Santos, G.; Faye, I.; Kroon, R.; Weken, H. Establishing the Transferability of Best Practice in EV Policy across EU Borders. Transp. Res. Procedia 2016, 14, 2574-2583. [CrossRef]

14. UK Government. Decarbonising Transport. Traffic Eng. Control 2020, 51, 246-248.

15. UK Government. Outcome and Response to Ending the Sale of New Petrol, Diesel and Hybrid Cars and Vans. 2021. Available online: https:/ / www.gov.uk/government/consultations/consulting-on-ending-the-sale-of-new-petrol-diesel-and-hybri d-cars-and-vans/outcome/ending-the-sale-of-new-petrol-diesel-and-hybrid-cars-and-vans-government-response (accessed on 14 July 2021).

16. Mathieu, L. Transport \& Environment Further Information. How to Decarbonise the UK's Freight Sector by 2050. 2020. Available online: https:/ /www.transportenvironment.org/publications/how-decarbonise-uks-freight-sector-2050 (accessed on 14 July 2021).

17. Technology Roadmaps. Electrical Energy Storage Roadmap 2020; The Advanced Propulsion Centre UK Ltd.: Coventry, UK, 2020. Available online: https://www.apcuk.co.uk/technology-\%20roadmaps/ (accessed on 14 July 2021).

18. UK Government. Workplace Charging Scheme, Guidance for Applicants, Chargepoint Installers and Manufacturers; UK Government: London, UK, 2020; pp. 1-27.

19. Office for Low Emission Vehicles, UK Government. Electric Vehicle Homecharge Scheme: Guidance for Customers 2016; UK Government: London, UK, 2016.

20. High Power-Chademo Association. Available online: https:/ / chademo.com/technology/high-power/ (accessed on 28 June 2021).

21. Kane Mark. CharIN Develops Super Powerful Charger with over 2 MW of Power. Available online: https://insideevs.com/news /372749/charin-hpccv-over-2-mw-power/ (accessed on 28 June 2021).

22. Fawzy, S.; Osman, A.I.; Doran, J.; Rooney, D.W. Strategies for Mitigation of Climate Change: A Review. Environ. Chem. Lett. 2020, 18, 2069-2094. [CrossRef]

23. Largest Emission-Free Bus Fleet in Brabant and Europe. Available online: https://www.brabantbrandbox.com/smart-mobility/e lectric-public-transport-buses/ (accessed on 28 June 2021).

24. Oliveira, L.; Ulahannan, A.; Knight, M.; Birrell, S. Wireless Charging of Electric Taxis: Understanding the Facilitators and Barriers to Its Introduction. Sustainability 2020, 12, 8798. [CrossRef]

25. Han, L.; Wang, S.; Zhao, D.; Li, J. The Intention to Adopt Electric Vehicles: Driven by Functional and Non-Functional Values. Transp. Res. Part A Policy Pract. 2017, 103, 185-197. [CrossRef]

26. Nicolaides, D.; Cebon, D.; Miles, J. An Urban Charging Infrastructure for Electric Road Freight Operations: A Case Study for Cambridge UK. IEEE Syst. J. 2019, 13, 2057-2068. [CrossRef]

27. Riemann, R.; Wang, D.Z.W.; Busch, F. Optimal Location of Wireless Charging Facilities for Electric Vehicles: Flow Capturing Location Model with Stochastic User Equilibrium. Transp. Res. Part C Emerg. Technol. 2015, 58, 1-12. [CrossRef]

28. Machura, P.; Li, Q. A Critical Review on Wireless Charging for Electric Vehicles. Renew. Sustain. Energy Rev. 2019, 104, 209-234. [CrossRef]

29. Choi, S.Y.; Gu, B.W.; Jeong, S.Y.; Rim, C.T. Advances in Wireless Power Transfer Systems for Roadway-Powered Electric Vehicles IEEE J. Emerg. Sel. Top. Power Electron. 2015, 3, 18-36. [CrossRef]

30. Sandberg, A.B.; Klementsen, E.; Muller, G.; De Andres, A.; Maillet, J. Critical Factors Influencing Viability of Wave Energy Converters in Off-Grid Luxury Resorts and Small Utilities. Sustainability 2016, 8, 1274. [CrossRef]

31. Holstein, J.A. In-Depth Interviewing; Sage Publication: Thousand Oaks, CA, USA, 2021; pp. 103-119.

32. Zabala, A.; Sandbrook, C.; Mukherjee, N. When and How to Use Q Methodology to Understand Perspectives in Conservation Research. Conserv. Biol. 2018, 32, 1185-1194. [CrossRef]

33. Kougias, I.; Nikitas, A.; Thiel, C.; Szabó, S. Clean Energy and Transport Pathways for Islands: A Stakeholder Analysis Using Q Method. Transp. Res. Part D Transp. Environ. 2020, 78, 102180. [CrossRef] 
34. Hsieh, H.F.; Shannon, S.E. Three Approaches to Qualitative Content Analysis. Qual. Health Res. 2005, 15, 1277-1288. [CrossRef]

35. Lopez Jaramillo, O.; Stotts, R.; Kelley, S.; Kuby, M. Content Analysis of Interviews with Hydrogen Fuel Cell Vehicle Drivers in Los Angeles. Transp. Res. Rec. 2019, 2673, 377-388. [CrossRef]

36. Liu, C.; Deng, K.; Li, C.; Li, J.; Li, Y.; Luo, J. The Optimal Distribution of Electric-Vehicle Chargers across a City. In Proceedings of the IEEE International Conference on Data Mining, ICDM, New Orleans, LA, USA, 18-21 November 2017; pp. 261-270. [CrossRef]

37. Amditis, A.; Karaseitanidis, G.; Damousis, I.; Guglielmi, P.; Cirimele, V. Dynamic Wireless Charging for More Efficient FEVs: The FABRIC Project Concept. In Proceedings of the MedPower 2014, Athens, Greece, 2-5 November 2014; Volume 2014. [CrossRef]

38. Jabeen, F.; Olaru, D.; Smith, B.; Braunl, T.; Speidel, S. Electric Vehicle Battery Charging Behaviour: Findings from a Driver Survey. In Proceedings of the Australasian Transport Research Forum, ATRF, Gardens Point, QLD, Australia, 2-4 October 2013.

39. Daina, N.; Sivakumar, A.; Polak, J.W. Electric Vehicle Charging Choices: Modelling and Implications for Smart Charging Services. Transp. Res. Part C Emerg. Technol. 2017, 81, 36-56. [CrossRef]

40. Ashkrof, P.; Homem de Almeida Correia, G.; van Arem, B. Analysis of the Effect of Charging Needs on Battery Electric Vehicle Drivers' Route Choice Behaviour: A Case Study in the Netherlands. Transp. Res. Part D Transp. Environ. 2020, 787, 102206. [CrossRef]

41. Heidrich, O.; Hill, A.G.; Neaimeh, M.; Huebner, Y.; Blythe, T.P.; Dawson, R.J. How Do Cities Support Electric Vehicles and What Difference Does It Make. Technol. Forecast. Soc. Chang. 2017, 123, 17-23. [CrossRef]

42. Hardman, S.; Jenn, A.; Tal, G.; Axsen, J.; Beard, G.; Daina, N.; Figenbaum, E.; Jakobsson, N.; Jochem, P.; Kinnear, N.; et al. A Review of Consumer Preferences of and Interactions with Electric Vehicle Charging Infrastructure. Transp. Res. Part D Transp. Environ. 2018, 62, 508-523. [CrossRef]

43. Shekhar, A.; Prasanth, V.; Bauer, P.; Bolech, M. Economic Viability Study of an On-Road Wireless Charging System with a Generic Driving Range Estimation Method. Energies 2016, 9, 76. [CrossRef]

44. García-Villalobos, J.; Zamora, I.; San Martín, J.I.; Asensio, F.J.; Aperribay, V. Plug-in Electric Vehicles in Electric Distribution Networks: A Review of Smart Charging Approaches. Renew. Sustain. Energy Rev. 2014, 38, 717-731. [CrossRef]

45. Deflorio, F.; Castello, L. Dynamic Charging-While-Driving Systems for Freight Delivery Services with Electric Vehicles: Traffic and Energy Modelling. Transp. Res. Part C Emerg. Technol. 2017, 81, 342-362. [CrossRef]

46. König, A.; Nicoletti, L.; Schröder, D.; Wolff, S.; Waclaw, A.; Lienkamp, M. An Overview of Parameter and Cost for Battery Electric Vehicles. World Electr. Veh. J. 2021, 12, 21. [CrossRef]

47. Liu, Z.; Song, Z. Robust Planning of Dynamic Wireless Charging Infrastructure for Battery Electric Buses. Transp. Res. Part C Emerg. Technol. 2017, 83, 77-103. [CrossRef]

48. Philipsen, R.; Schmidt, T.; Ziefle, M. A Charging Place to Be-Users' Evaluation Criteria for the Positioning of Fast-Charging Infrastructure for Electro Mobility. Procedia Manuf. 2015, 3, 2792-2799. [CrossRef]

49. Philipsen, R.; Schmidt, T.; Van Heek, J.; Ziefle, M. Fast-Charging Station Here, Please! User Criteria for Electric Vehicle FastCharging Locations. Transp. Res. Part F Traffic Psychol. Behav. 2016, 40, 119-129. [CrossRef]

50. Kostopoulos, E.D.; Spyropoulos, G.C.; Kaldellis, J.K. Real World Study for the Optimal Charging of Electric Vehicle. Energy Rep. 2020, 6, 418-426. [CrossRef]

51. Moon, S.; Kim, B.C.; Cho, S.Y.; Ahn, C.H.; Moon, G.W. Analysis and Design of a Wireless Power Transfer System with an Intermediate Coil for High Efficiency. IEEE Trans. Ind. Electron. 2014, 61, 5861-5870. [CrossRef]

52. Hutchinson, L.; Waterson, B.; Anvari, B.; Naberezhnykh, D. Potential of Wireless Power Transfer for Dynamic Charging of Electric Vehicles. IET Intell. Transp. Syst. 2019, 3, 3-12. [CrossRef]

53. Final Report Summary-FASTINCHARGE (Innovative Fast Inductive Charging Solution for Electric Vehicles) I Report Summary I FASTINCHARGE I FP7 I CORDIS I European Commission. Available online: https:/ / cordis.europa.eu/project/id/314284 / reporting (accessed on 28 June 2021).

54. Zoepf, S.; Mackenzie, D.; Keith, D.; Chernicoff, W. Charging Choices and Fuel Displacement in a Large-Scale Demonstration of Plug-in Hybrid Electric Vehicles. Transp. Res. Rec. 2013, 2385, 1-10. [CrossRef]

55. Azadfar, E.; Sreeram, V.; Harries, D. The Investigation of the Major Factors Influencing Plug-in Electric Vehicle Driving Patterns and Charging Behaviour. Renew. Sustain. Energy Rev. 2015, 42, 1065-1076. [CrossRef]

56. Guo, F.; Yang, J.; Lu, J. The Battery Charging Station Location Problem: Impact of Users' Range Anxiety and Distance Convenience. Transp. Res. Part E Logist. Transp. Rev. 2018, 114, 1-18. [CrossRef]

57. Sarrafan, K.; Muttaqi, K.M.; Sutanto, D.; Town, G.E. An Intelligent Driver Alerting System for Real-Time Range Indicator Embedded in Electric Vehicles. IEEE Trans. Ind. Appl. 2017, 53, 1751-1760. [CrossRef]

58. Castle, C.J.E.; Crooks, A.T. Principles and Concepts of Agent-Based Modelling for Developing Geospatial Simulations; Centre for Advanced Spatial Analysis, University College London (UCL): London, UK, 2006.

59. Hosseini, S. Development of a Bayesian Network Model for Optimal Site Selection of Electric Vehicle Charging Station. Int. J. Electr. Power Energy Syst. 2018, 105, 110-122. [CrossRef] 